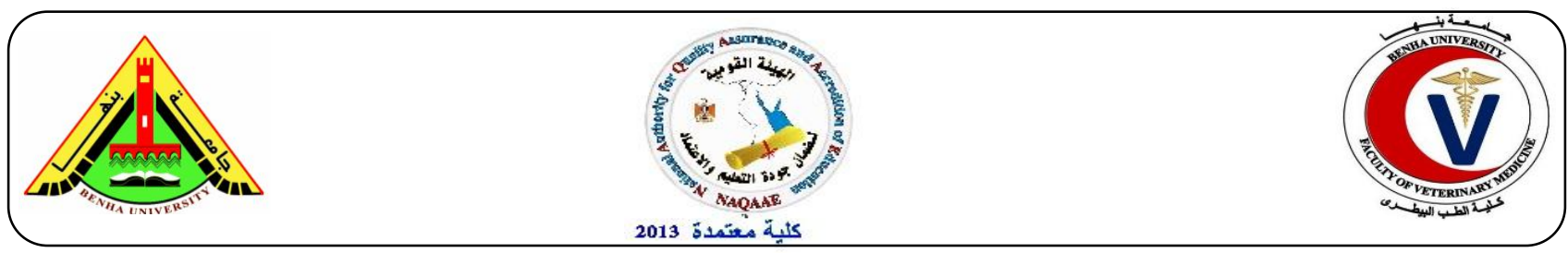

\title{
Evaluation of combined inactivated vaccines against avian influenza subtypes [H5N1, H9N2] and avian infectious Bronchitis in chicken using montanide and paraffin oil adjuvants
}

\author{
El-Sayed, M. H.N1; El-Bagoury, G. F²; El-Habbaa, A. S²; El-Makaky, H. M1 \\ ${ }^{1}$ Newcastle Disease Vaccine Research Department, Veterinary Serum and Vaccine Research Institute, \\ Abbasia, Cairo. \\ ${ }^{2}$ Department of Virology, Faculty of Veterinary Medicine, Benha University.
}

\section{A B S T R A C T}

The goal of the presented work was to prepare and evaluate physical characters and immunogenicity of a combined inactivated Avian Influenza Virus (AIV) H5N1, H9N2 subtypes and Infectious Bronchitis Virus (IBV), strain D-88 oil emulsion vaccines. The prepared vaccines were sterile and safe. Also, they were ensured to be water in oil (W/O) emulsions using drop test, conductivity (zero $\mathrm{mS} / \mathrm{cm}$ ). Particle size were $950 \mathrm{~nm}$ and $1050 \mathrm{~nm}$ and dynamic viscosities were 19.52 Mpa.s and 39.65 Mpa.s for the vaccine with Montanide ${ }^{\mathrm{TM}}$ ISA 71 RVG adjuvant and the vaccine with paraffin oil adjuvant, respectively. They showed stability for 24 months at $4{ }^{\circ} \mathrm{C}$ with no separation. Combined inactivated oil emulsion vaccines induced cellular and humoral immune responses in vaccinated chicks. The vaccine with Montanide ${ }^{\mathrm{TM}}$ ISA $71-\mathrm{RVG}$ adjuvant provided $100 \%$ protection percent for AIV H5N1 without shedding of AIV H9N2 and IBV in comparison to the combined vaccine with paraffin oil adjuvant that gave $84 \%$ protection percent for AIV H5N1 and shedding of AIV H9N2 and IBV occurred $6^{\text {th }}$ day post challenge. Montanide ${ }^{\text {TM }}$ 71-RVG adjuvant has the flexible ratio of oil and antigenic media in the vaccine (60:40) allowed using large amount of virus that showed good impact on its immunogenicity, over the paraffin oil adjuvant which has restricted ratio of oil and antigenic media of the vaccine (73:27).

Keywords: AIVs, H5N1, H9N2, IBV, inactivated oil-emulsion vaccine.

(http://www.bvmj.bu.edu.eg)

(BVMJ-34(2): 121-139, 2018)

\section{INTRODUCTION}

Avian influenza virus (AIV) and infectious bronchitis virus (IBV) are important viral pathogens in commercial poultry flocks in Egypt causing respiratory manifestations and massive mortalities (Kayali et al., 2016; Kaoud, 2017; Heba et al., 2016). Avian influenza (AI) is a viral disease caused by type A influenza viruses belonging to family Orthomyxoviridae (Olsen et al., 2006).
The virus particle has an envelope with glycoprotein projection with haemagglutinin (HA) and neuraminidase (NA) activity. These two Surface antigens are the basis of the serologic identity of the influenza virus using the letters $\mathrm{H}$ and $\mathrm{N}$ with the appropriated numbers in the virus designation. There are $16 \mathrm{HA}$ and 9 NA antigens described among the type (A) influenza virus (Fouchier et al., 
2005; Dugan et al, 2008). AIV can be classified into two categories; Low Pathogenic Avian Influenza Virus (LPAIV) and High Pathogenic Avian Influenza Virus (HPAIV), based on the severity of illness caused in domestic birds (Capua and Alexander, 2004). HPAIV may cause up to $100 \%$ mortality as subtypes $\mathrm{H} 5$ and $\mathrm{H} 7$, although not all viruses of these subtypes cause HPAIVs, on the other hand, LPAIVs cause mild to moderate infectious in various domestic and wild bird specious (Mo et al., 1997; Alexander, 2000).

Various subtypes of AIVs H5N1 and H9N2 are circulating among poultry flocks causing severe disease outbreaks with high morbidity and mortality (Cameron et al., 2000; Xu et al., 2007; OIE 2008; Nagarajan et al., 2009; Abbas et al., 2010; Jeong et al., 2010; Kim et al., 2010).

In Egypt, the HPAIV (H5N1) had emerged since February 2006 as the cause of sever disease and high mortality in chickens in production farms and village-based production and causing a great hazard to humans (Aly et al., 2006).

AI H9N2 viruses are characterized as low pathogenic viruses among multiple avian species in Asia, the Middle East, Africa and Europe (Guo, 2002). In Egypt, AIV H9N2 was isolated in December 2010 to May 2011 in chickens, quails and turkeys (AbdelMoneim et al., 2012a and Arafa et al., 2012a,b). The co-infection of H9N2 with $\mathrm{H} 5 \mathrm{~N} 1$ was also reported in many cases in poultry in Egypt (Arafa et al., 2012b; Monne et al., 2013; Kayali et al., 2014). Also, some strains of IBV were isolated from several broiler flocks during the H9N2 outbreaks (Nouri et al., 2003; Shapouri et al., 2004; Haqshenas et al., 2005).

Infectious bronchitis virus (IBV) causes a highly contagious respiratory disease and some nephropathogenic strains cause nephritis with the result of significant mortalities in commercial young chickens (Liu and Kong, 2004). It also causes decrease in egg production and egg quality in layers and breeders (Gelb et al., 1991). IBV belonged to genus Gammacorona virus; family Coronaviridae (Carstens, 2009). More than 20 serotypes of IBV were distributed worldwide (Sjaak de Wit et al., 2011). In Egypt, IBV strains have been isolated from chicken flocks (Abd El Rahman et al., 2015). Although these isolates of IBV varied genotypically, they were similar to Massachusetts, D3128, D274, D08880, 793B (4/91 and CR88), IS/885/00 and Egypt/BeniSuef/01 strains (Sultan et al., 2015). However, variant strains of IBV, Egy/Var- II (Ck/Eg/BSU-2, 3/2011), were resembling IS/885/00 strain based on sequence of the HVR-3 of $\mathrm{S}$ gene (Abdel-Moneim et al., 2012b).

Vaccination is one of the most important control measures against AIVs H5N1 and H9N2 and IBV (Peyre et al., 2007; Sultan et al., 2004; El-Mahdy et al., 2010). Quality of the adjuvant has direct impact on safety and efficacy of the vaccine, so good physical properties of the inactivated oil emulsion vaccine could in turn increase the immune response to this vaccine. High quality oil emulsion vaccine should be stable, with low viscosity to ease injectability and produce suitable antibody titer in vaccinated birds (stone et al, 1983).

The present study was designed to formulate multivalent inactivated $\mathrm{H} 5 \mathrm{~N} 1$ and $\mathrm{H} 9 \mathrm{~N} 2$ AIVs and IBV oil emulsion vaccine using different adjuvants as Montanide ${ }^{\mathrm{TM}}$ ISA 71R VG and Paraffin which would be reflected on the immunological response.

\section{Materials and methods}

2.1. AI Virus strains:

AI (H5N1) vaccinal strain: 
The Highly pathogenic (HP) Reasortant Avian Influenza Virus $\left(\mathrm{H}_{5} \mathrm{~N}_{1}\right)$ subtype Egypt/ Re-1\&2 strains seed virus obtained from National Research Center (NRC), [A/chicken/ Q1995D/2010 (strain-1) and A/duck/M2583A/2010 (strain-2)]. The virus strains were egg adapted for $8^{\text {th }}$ passage on specific pathogen free-embryonated chicken egg (SPF-ECE) with HA titer $2^{10} / 50 \mu 1$ and infectivity titer $10^{9}$ EID50/0.1 $\mathrm{ml}$ (OIE manual 2004). It was used as the seed virus for vaccines preparation.

\section{AI H5N1challenge strain:}

Virulent strain of highly pathogenic avian influenza virus (HPAIV) H5N1 subtype (A/Chicken/Egypt/1063/2010) obtained from NRC with infectivity titer of $10^{5} \mathrm{EID}_{50} / \mathrm{ml}$ used for challenging of vaccinated chicks and are kept under observation for 2 weeks. AI (H9N2) virus strain:

The low pathogenic Avian Influenza Virus (LPAIV) H9N2 subtype (A/chicken/Egypt/D4692A /2012 obtained from NRC, Egypt. The virus was isolated from chicken farms at Dakahlia governorate and propagated on SPF chicken eggs with original titer $10^{9.5} \mathrm{EID}_{50} / \mathrm{ml}$ and $2^{11} \mathrm{HA}$ activity (OIE manual 2004). It was used as the seed virus for vaccines preparation and also for challenging of vaccinated chicks.

Infectious bronchitis (D-88) Vaccinal strain:

Local Nephropathogenic strain IBV was isolated from IBV-vaccinated broiler chickens 24 day old at Dakahlia, with a history of respiratory and renal signs (Abdel-Moneim et al., 2006). The local isolate was matched for 96\% with isolated strain [Egypt/F/03strain], with accession No. DQ487085 (NCBI) the isolated strain titer was $10^{6}$ EID50/ml. It was kindly obtained from NRC, Egypt.

Infectious bronchitis (M41) vaccinal strain:

The Infectious bronchitis virus (IBV) as Massachusetts M41 strain supplied by department of animal science and agriculture biochemistry, university of Delaware, New
York, USA. The Master seed with original titer $10^{10.5} \mathrm{EID} 50 / \mathrm{ml}$. The virus used for challenging of chicks against (local Nephropathogenic IBV strainEgypt/F/03strain-NCBI). The challenge virus dose was adjusted to $0.1 \mathrm{ml}$ containing $10^{4}$ $\mathrm{EID}_{50} / \mathrm{ml} / \mathrm{bird}$ (OIE, 2008; Tawfik et al., 2013).

\subsection{Embryonated Chicken Eggs (ECEs):}

Specific pathogen free embryonated chicken eggs (SPF- ECEs) were purchased from the specific pathogen free egg project, Kom Oshim, El-Fayoum Governorate. The eggs were incubated at $37^{\circ} \mathrm{C}$ and $80 \%$ humidity until inoculated at 9-11 days of age via allantoic sac route. They were used for propagation \& titration of the seed influenza viruses used for preparation of the vaccinal patches and testing the safety of prepared inactivated virus suspensions.

\subsection{Experimental chicks:}

Two hundred and ten (210), one-day-old chicks were purchased from specific pathogen free poultry project, Kom Oshim, EL-Fayoum Governorate. They were floor reared, fed on commercial poultry ration, and kept under strict hygienic measures throughout the experiment. The chicks were used for studying the safety and evaluating of the prepared vaccines.

\subsection{Vaccine formulation:}

Propagation of the Virus in SPF-ECEs:

AI Virus [H5N1, H9N2] strains propagation in embryonated chicken eggs were applied according to Garcia et al. (1998), while IB virus according to OIE, (2008).

Virus Titration in Embryonated Chicken Egg:

Estimation EID50 of the viruses used were calculated according to Reed and Meunch (1938). Titer of AIV (H5N1) was $9.5 \log 10$ EID50/ml and $10.5 \log 2 \mathrm{HAU} / 50 \mu \mathrm{l}$, while AIV (H9N2) titer was $10 \log 10$ EID50/ml and 
$11 \log 2 \mathrm{HAU} / 50 \mu \mathrm{l}$, using infectivity titration and HA test respectively. Also, titer of IBV was $8.2 \log 10 \mathrm{EID} 50 / \mathrm{ml}$ using infectivity titration test.

Rapid Plate Hemagglutination (HA) Test:

It was carried out according to the standard method described by Anon (1971)Virus

Inactivation of Viruses:

Formalin working solution, $\mathrm{HCHO}, 37 \%$ Analar, BDH. it was diluted in saline in concentration $0.1 \%$ for AIVs (OIE manual 2004), while in IBV the final concentration was $0.01 \%$ of the total volume (Beard, 1989). Vaccine preparation:

Inactivated Combined vaccine with Montanide $^{\mathrm{TM}}$ ISA 71-RVG oil adjuvant:

A combined vaccine was prepared as water in oil (W/O) emulsion by mixing equal weights from the inactivated AIV H5N1, AIV H9N2 and IBV then this aqueous phase was mixed with MontanideTM ISA 71 RVG oil adjuvant in a ratio of 40:60 weight per weight (Ben Arous et al., 2013).

Inactivated Combined vaccine with paraffin oil adjuvant:

A combined vaccine was prepared as water in oil (W/O) emulsion by mixing equal weights from the inactivated AIV H5N1, AIV H9N2 and IBV, with both the oil soluble surfactant (span 80) and the aqueous soluble surfactant (tween 80) were added to the oil phase (Paraffin oil), (Daoud et al., 2002). This method was modified through addition of aluminum stearate (El-Sayed, 2014), then the aqueous-phase (Inactivated virus suspension) was added to the oil-phase at a ratio 1:3 and the hydrophilic lipophilic balance (HLB) was adjusted to 7.0 as described by Schick, (1966) and Stone, (1988).

\subsection{Quality control of the prepared vaccines: Sterility test:}

Experimental batches of the prepared vaccines were tested for sterility and freedom from any fungal or bacterial contaminants by culturing on specific media (Saburaoud glucose agar searching for fungus contamination after incubation at $25^{\circ} \mathrm{C}$ for 14 days, Nutrient agar media and Thioglycolate broth searching for aerobic and anaerobic bacterial contamination, respectively after incubation at $37^{\circ} \mathrm{C}$ for 72 hours).

Safety test:

Two groups, each of 10 chicks of 3 weeks old were inoculated with 2 field doses $(1 \mathrm{ml})$ of the prepared vaccines at the nap of the neck in addition to a control non-vaccinated group. The vaccinated chicks were observed for 2 weeks for any signs of local reaction or appearance of any clinical signs. After 5 days of inoculation, some birds were subjected to post mortem examinations to detect any pathological lesions.

Physical stability:

Physical properties of the emulsions were determined as Drop test, Conductivity test, Particle size, Dynamic Viscosity and Realtime test.

\subsection{Experimental design:}

Physical properties of the prepared vaccines: They were determined as describe by Brugh et al., (1983) and Stone et al., (1988).

Efficacy of prepared vaccines:

Both prepared combined inactivated AIVs H5N1, H9N2 and IBV vaccine with Montanide $^{\mathrm{TM}}$ ISA 71-RVG oil adjuvant and combined inactivated AIVs H5N1, H9N2 and IBV vaccine with paraffin oil adjuvant were chosen regarding to their physical properties and subjected for evaluation of both cell mediated immune response and humoral immune response.

\section{Potency of Prepared vaccines}

Challenge experiment was carried out to determine the potency of the prepared vaccines. A total of 450 one-day old SPF chicks were reared under complete hygienic measures in special isolators, at 28 days of age the chicks were divided into 9 equal 
subgroups groups each of 50 chicks and treated as follow:

G1: Chicks inoculated with combined inactivated AIVs H5N1, H9N2 and IBV vaccine with Montanide ${ }^{\mathrm{TM}}$ ISA $71-\mathrm{RVG}$ as adjuvant. It was divided into three subgroups G1-A (Challenged with HPAIV H5N1 strain), G1-B (challenged with AIV H9N2 strain) and G1-C (Challenged with IBV (M41) strain.

G2: Chicks inoculated with combined inactivated AIVs H5N1, H9N2 and IBV vaccine with paraffin oil as adjuvant. It was divided into three subgroups G2-A (Challenged with HPAIV H5N1 strain), G2-B (challenged with AIV H9N2 strain) and G3-C (Challenged with IBV (M41) strain.

G3: Chicks kept in separate isolators as nonvaccinated control group. It was divided into three subgroups G3-A (control group for AIV H5N1), G3-B (control group for AIV H9N2) and G3-C (control group for IBV).

\subsection{Samples:}

Whole blood samples:

Jugular blood samples from vaccinated and non-vaccinated chicks were collected with anticoagulant (Heparin 20-40 IU/ml) at 3, 7, 10, 14, 21 and 28 days post vaccinations for lymphocyte blastogenesis assay and phagocytic activity test.

Serum samples:

erum samples were collected from all chicks (vaccinated and non- vaccinated) weekly till $10^{\text {th }}$ week post vaccination then every 2 week till the $31^{\text {th }}$ week post vaccination. The sera were inactivated at $56^{\circ} \mathrm{C}$ for 30 minutes, and then stored at $-20^{\circ} \mathrm{C}$ until used in $\mathrm{HI}$ test.

\subsection{Evaluation of cellular immune response} for prepared vaccine:

Evaluation of lymphocyte transformation:

Separation of lymphocytes, determination of viable cell number, and setting up of lymphocytes was performed depending on the instructions of cell proliferation (XTT) kit
(ATCC, USA) and the test was performed according to Scudiero et al., (1988). The test was applied according to the method described by Lucy, (1977) and Lee, (1984).

Evaluation of phagocytic activity of chicken macrophages by using Candida Albicans:

Separation of macrophages by ficol hypaque and cultivation of mononuclear cells were performed according to Richardson and Smith, (1981) and modified by Hussien, (1989) .The percent of phagocytosis and phagocytic index was calculated as follow:

phagocytic percentage $=\frac{\text { no of phagocytes which ingest Candida }}{\text { total no of phagocytes }} \times 100$

phagocytic index $=\frac{\text { total no of phagocytes which ingest more than two Candida }}{\text { total no of phagocytes which ingest Candida }}$

Evaluation of the humoral immune response for prepared vaccines using Hemagglutination (HA) and Hemagglutination inhibition (HI) test:

The Hemagglutination (HA) and hemagglutination inhibition (HI) test were carried out following the recommendation of (OIE-Manual, 2004). The used antigens in HI test should be prepared from the pure, well identified homologous AIV H5N1 (A/Chicken/Egypt/1063/2010) and AIV H9N2 (A/chicken/Egypt/D4692A/2012).

Enzyme Linked Immunosorbent Assay (ELISA):

Commercial ELISA kits used for monitoring serum antibody responses against IBV. The antigens used in the kits are broadly crossreactive among serotypes and allow for general serological monitoring of vaccinal responses and field challenges according to Snyder et al., (1986). ELISA Kit was obtained from ID.VET, France innovative diagnostic poultry immune assays. ID SCREEN IBV indirect test kit (IBVS ver 0614 GB); Batch No: 949, product code: IBVS.

\subsection{Challenge of chicks vaccinated with AI} vaccine:

Challenge with HPAIV (H5N1) Strain 
Four weeks old chickens (vaccinated and un vaccinated control) were challenged by 0.5 $\mathrm{cm} / \mathrm{bird}$ by $\mathrm{I} / \mathrm{M}$ route of virulent strain of HPAIV H5N1 subtype (A/Chicken/Egypt/1063/2010) with infectivity titer of $10^{5} \quad \mathrm{EID}_{50} / \mathrm{ml}$. The challenged birds were observed for 15 days and collect serum samples during challenge period, dead birds through this time were recorded and examined for $\mathrm{p} / \mathrm{m}$ lesions.

Protection $\%=\frac{\text { No.of survival }}{\text { total No.of challenge of birds }} \mathrm{X} 100$

Challenge with Infectious bronchitis (M41) Vaccinal strain;

Four weeks old chickens (vaccinated and unvaccinated control) were challenged by Infectious bronchitis (M41) Vaccinal strain. Each bird received a dose of $0.1 \mathrm{ml}$ intranasal of IBV strain $\left(10^{4} \mathrm{EID}_{50} / \mathrm{ml}\right)$ and observed for 15 days after challenge, for clinical signs and postmortem lesion in trachea and kidney. Tracheal and cloacal swabs were collected at $2^{\text {nd }}, 4^{\text {th }}$ and $6^{\text {th }}$ days post challenge to determine the virus shedding using (RT-PCR)

Challenge with LPAIV (H9N2) Strain;

Four weeks old chickens (vaccinated and unvaccinated control) were challenged with the LPAI (A/chicken /Egypt/D4692A/2012 H9N2). The birds were inoculated by the intra-nasal $(100 \mu \mathrm{l})$ of allantoic fluid containing $10^{6}$ EID50 of the virus. Tracheal and cloacal swabs were collected at $2^{\text {nd }}, 4^{\text {th }}$ and $6^{\text {th }}$ days post challenge to determine the virus shedding using real time reverse transcription PCR (RRT-PCR).

2.11. Detection of AIV H9N2 and IBV shedding using RRT-PCR:

The numbers of viral genome copies were quantified in a TaqMan ${ }^{\circledR}$ real time RT-PCR targeting Influenza (A) hemagglutination gene and IBV nucleoprotein gene using RNA extraction kit (QIA amp Viral RNA Mini Kit, QIAGEN, catalogue No. 52904), real time PCR master mix (QuantiTect probe RT-PCR catalogue no. 204443) and real-time quantification of RNA targets using primers and probes supplied from Metabion (Germany). An absolute quantification was done relatively to a standard curve based on tenfold dilution of an in vitro transcribed RNA template of the challenged virus. The samples were tested using thermal cycling conditions for gene-specific Probe and Primer sets using protocol and methods of Ben Shabat et al., (2010) for AIV H9N2 and Meir et al., (2010) for IBV. Chickens were sampled and tested on individual basis. $\mathrm{Ct}$ value of 40 was selected as the cut-off between positive and negative result and samples with higher $\mathrm{Ct}$ were considered as negative for AIV and IBV. This was decided according to the standard curve.

Table 1: Oligonucleotide Primers and probes.

\begin{tabular}{|c|c|c|c|}
\hline $\begin{array}{l}\text { V } \\
\text { ir } \\
\text { us }\end{array}$ & $\begin{array}{l}\mathrm{G} \\
\mathrm{e} \\
\mathrm{n} \\
\mathrm{e}\end{array}$ & Primer/ probe sequence 5'-3' & $\begin{array}{l}\text { Referen } \\
\text { ce }\end{array}$ \\
\hline $\begin{array}{l}\mathrm{H} \\
9\end{array}$ & $\mathrm{H}$ & $\begin{array}{l}\text { H9F- } \\
\text { GGAAGAATTAATTATTATTGGT } \\
\text { CGGTAC } \\
\text { H9R- } \\
\text { GCCACCTTTTTCAGTCTGACATT } \\
\text { H9 Probe } \\
\text { [FAM]AACCAGGCCAGACATTGC } \\
\text { GAGTAAGATCC[TAMRA] }\end{array}$ & $\begin{array}{c}\text { Ben } \\
\text { Shabat } \\
\text { et al., } \\
2010\end{array}$ \\
\hline $\begin{array}{l}\text { I } \\
\text { B }\end{array}$ & $\mathrm{N}$ & $\begin{array}{l}\text { AIBV-fr- } \\
\text { ATGCTCAACCTTGTCCCTAGCA } \\
\text { AIBV-as- } \\
\text { TCAAACTGCGGATCATCACGT } \\
\text { AIBV-TM } \\
\text { [FAM]TTGGAAGTAGAGTGACGC } \\
\text { CCAAACTTCA [TAMRA] }\end{array}$ & $\begin{array}{c}\text { Meir } \text { et } \\
\text { al., } 2010\end{array}$ \\
\hline
\end{tabular}

\section{RESULTS}

Sterility and safety of the prepared vaccines:

The prepared vaccines were free from aerobic and anaerobic bacteria and fungi. They were completely inactivated as indicated by absence of any pathological lesions, HA activity for AIVs H5N1, H9N2 and/or deaths of inoculated embryos being inoculated in 9 days old, SPF-ECEs through the allantoic sac and candled daily for 6 days. There was no local or systemic reaction and no mortalities among vaccinated chicks indicating safety of both inactivated combined [H5N1, H9N2 and 
IBV] vaccine with Montanide ${ }^{\mathrm{TM}}$ ISA 71-RVG oil adjuvant and inactivated combined [H5N1, H9N2 and IBV] vaccine with paraffin oil adjuvant.

Assessment of physical characters of the prepared vaccine:

The prepared vaccines were ensured to be water-in-oil (w/o) emulsion type using drop test, this $\mathrm{W} / \mathrm{O}$ emulsion showed $0 \mathrm{mS} / \mathrm{cm}$ conductivity. Inactivated combined [H5N1, H9N2 and IBV] vaccine with MontanideTM ISA 71-RVG oil adjuvant showed 19.52 m.pa.s viscosity, $950 \mu \mathrm{m}$ particle size and long duration of stability equal or more than 104 weeks at $+4 \mathrm{C}^{\circ}$ no separation as water release or oil release, while inactivated combined [H5N1, H9N2 and IBV] vaccine with paraffin oil adjuvant showed 39.65 m.pa.s viscosity, $1050 \mu \mathrm{m}$ particle size and long duration of for 24 months at $+4 \mathrm{C}^{\circ}$ with no separation as water release or oil release as shown in table (2).

\section{Cell mediated immune response:}

Lymphocyte blastogenesis showed significant cell proliferation expressed by optical density induced in vaccinated chicks vaccinated by both inactivated combined [H5N1, H9N2 and IBV] vaccine with Montanide ${ }^{\mathrm{TM}}$ ISA 71-RVG oil adjuvant and inactivated combined [H5N1, H9N2 and IBV] vaccine with paraffin oil adjuvant from the $3^{\text {rd }}$ day post vaccination (DPV) and increased to reach a maximum value $14^{\text {th }}$ DPV. It was noticed that cell proliferation expressed by optical density induced in chicks vaccinated with inactivated combined [H5N1, H9N2 and IBV] vaccine with Montanide ${ }^{\mathrm{TM}}$ ISA 71-RVG oil adjuvant showed higher values than that of chicks vaccinated with inactivated combined [H5N1, H9N2 and IBV] vaccine with paraffin oil adjuvant. All the results were compared with that SPF chicks non-vaccinated kept as negative control that had no lymphocyte proliferation as shown in table (3).
Both phagocytic percent and phagocytic index of macrophages were significantly increased $7^{\text {th }}$ DPV to reach maximum values at $14^{\text {th }}$ DPV in vaccinated chicks both inactivated combined [H5N1, H9N2 and IBV] vaccine with Montanide ${ }^{\mathrm{TM}}$ ISA 71-RVG oil adjuvant and inactivated combined [H5N1, H9N2 and IBV] vaccine with paraffin oil adjuvant, when compared with that of non-vaccinated chicks kept as negative control that had no macrophage activity as shown in table (4).

\section{Humoral immune response:}

Chicks vaccinated with inactivated combined [H5N1, H9N2 and IBV] vaccine with Montanide $^{\mathrm{TM}}$ ISA 71-RVG oil adjuvant, showed increased mean $\log 2 \mathrm{HI}$ antibody titer (5.33 $\log 2)$ against AIV H5N1 from the 1st week post vaccination (WPV), then reached the highest HI antibody titer $(10 \log 2)$ at the $3^{\text {rd }} \mathrm{WPV}$ and remained in suitable levels (4.33 $\log 2)$ till $31^{\text {st }}$ WPV. Chicks vaccinated with inactivated combined [H5N1, H9N2 and IBV] vaccine with paraffin oil adjuvant, showed increased mean $\log 2 \mathrm{HI}$ antibody titer $(4 \log 2)$ against AIV H5N1 from the 1st week post vaccination (WPV), then reached the highest HI antibody titer $(8.3 \log 2)$ at the $5^{\text {th }}$ WPV, then declined to $(4.3 \log 2)$ at the $21^{\text {st }}$ WPV then declined gradually to reach the lowest HI antibody titer $(1.33 \log 2)$ at the $31^{\text {st }}$ WPV. These results were compared with that of nonvaccinated chicks kept as negative control that had no antibody against H5N1 as shown in table (5).

Chicks vaccinated with inactivated combined [H5N1, H9N2 and IBV] vaccine with

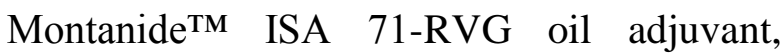
showed increased mean $\log 2 \mathrm{HI}$ antibody titer (5.6 $\log 2)$ against AIV H9N2 from the 1st week post vaccination (WPV), then reached the highest HI antibody titer $(10 \log 2)$ at the $4^{\text {th }}$ WPV and remained in suitable levels (4.33 $\log 2$ ) till $31^{\text {st }}$ WPV. Chicks vaccinated with inactivated combined [H5N1, H9N2 and IBV] 
vaccine with paraffin oil adjuvant, showed increased mean $\log 2 \mathrm{HI}$ antibody titer $(3 \log 2)$ against AIV H9N2 from the 1st week post vaccination (WPV), then reached the highest HI antibody titer $(7.3 \log 2)$ at the $4^{\text {th }}$ WPV, then declined to $(4 \log 2)$ at the $23^{\text {rd }}$ WPV then declined gradually to reach the lowest HI antibody titer $(1.0 \log 2)$ at the $31^{\text {st }}$ WPV. These results were compared with that of nonvaccinated chicks kept as negative control that had no antibody against H9N2 as shown in table (6).

Chicks vaccinated with inactivated combined [H5N1, H9N2 and IBV] vaccine with

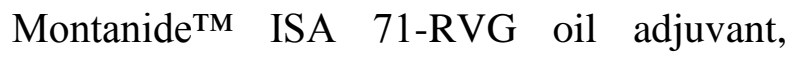
showed increased antibody titer measured by mean ELISA optical density (453) against IBV from the 1st week post vaccination (WPV), then reached the highest values (2108) at the $4^{\text {th }} \mathrm{WPV}$ and remained in suitable levels (1204) till $21^{\text {st }}$ WPV. Chicks vaccinated with inactivated combined [H5N1, H9N2 and IBV] vaccine with paraffin oil adjuvant, showed increased antibody titer measured by mean ELISA optical density (586) against IBV from the 1st week post vaccination (WPV), then reached the highest HI antibody titer (1862) at the $4^{\text {th }}$ WPV, then declined to (542) at the $21^{\text {st }}$ WPV. These results were compared with that of nonvaccinated chicks kept as negative control that had no antibody against IBV as shown in table (7).

\section{Potency of the prepared vaccine:}

Both vaccinated and non-vaccinated control chicks were challenged 28 days post vaccination using virulent strains of AIVs H5N1, H9N2 and IBV.

The protection percent against HPAIV H5N1 were $100 \%$ in chicks vaccinated with inactivated combined [H5N1, H9N2 and IBV] vaccine with MontanideTM ISA 71-RVG oil adjuvant and $84 \%$ in chicks vaccinated with inactivated combined [H5N1, H9N2 and IBV] vaccine with paraffin oil adjuvant, compared with $0 \%$ for control non-vaccinated chicks as shown in table (8).

Evaluation of shedding of AIV H9N2 were zero \% using RRT-PCR in challenged chicks vaccinated with both inactivated combined [H5N1, H9N2 and IBV] vaccine with Montanide $^{\mathrm{TM}}$ ISA 71-RVG oil adjuvant and inactivated combined [H5N1, H9N2 and IBV] vaccine with paraffin oil adjuvant, compared with $100 \%$ shedding for control nonvaccinated chicks in tracheal swaps at $2^{\text {nd }}, 4^{\text {th }}$ and $6^{\text {th }}$ day post challenge as shown in table (9).

Evaluation of shedding of IBV were zero \% using RRT-PCR in challenged chicks vaccinated with inactivated combined [H5N1, H9N2 and IBV] vaccine with Montanide ${ }^{\mathrm{TM}}$ ISA 71-RVG oil adjuvant and shedding of IBV using RRT-PCR in challenged chicks vaccinated with inactivated combined [H5N1, H9N2 and IBV] vaccine with paraffin oil adjuvant, were zero $\%$ at $2^{\text {nd }}$ day post challenge then shedding occurred at $4^{\text {th }}$ and $6^{\text {th }}$ day post challenge, compared with $100 \%$ shedding for control non-vaccinated chicks in tracheal swaps at $2^{\text {nd }}, 4^{\text {th }}$ and $6^{\text {th }}$ day post challenge as shown in table (10). 
Table 2: physical properties of prepared oil emulsion combined inactivated vaccines against avian AI [H5N1, H9N2] and IBV.

\begin{tabular}{|c|c|c|c|c|c|c|c|}
\hline \multirow[t]{2}{*}{ Vaccine } & \multicolumn{2}{|c|}{ Emulsion type } & \multirow{2}{*}{$\begin{array}{l}\text { Particle } \\
\text { size }\end{array}$} & \multirow{2}{*}{$\begin{array}{l}\text { Dynamic } \\
\text { Viscosity }\end{array}$} & \multicolumn{3}{|c|}{$\begin{array}{c}\text { Emulsion stability per } \\
\text { week (real time test) }\end{array}$} \\
\hline & Drop test & Conductivity & & & $25^{\circ} \mathrm{C}$ & $37 \mathrm{C}^{\circ}$ & $+4 \mathrm{C}^{\circ}$ \\
\hline V1 & $\mathrm{W} / \mathrm{O}$ & & & & $\leq 64$ & $\geq 13$ & $\leq 104$ \\
\hline $\mathrm{V} 2$ & $\mathrm{~W} / \mathrm{O}$ & $0 \mathrm{mS} / \mathrm{cm}$ & $1050 \mu \mathrm{m}$ & 39.65 Mpa.s & $\leq 13$ & $\geq 4$ & $\geq 104$ \\
\hline
\end{tabular}

V1: Combined inactivated vaccine against avian AI [H5N1, H9N2] and IBV Montanide ${ }^{\text {TM }}$ ISA 71-RVG.

V2: Combined inactivated vaccine against avian AI [H5N1, H9N2] and IBV Paraffin adjuvant.

Table 3: Lymphocyte proliferation of chickens vaccinated with combined inactivated avian AI [H5N1, H9N2] and IBV oil emulsion vaccines expressed by delta optical density.

\begin{tabular}{ccccccc}
\hline \multirow{2}{*}{$\begin{array}{c}\text { Chick } \\
\text { group }\end{array}$} & \multicolumn{5}{c}{$\begin{array}{c}\text { Cell proliferation expressed by } \\
\text { optical density/day post-vaccination }\end{array}$} \\
\cline { 2 - 7 } & $3^{\text {rd }}$ & $7^{\text {th }}$ & $10^{\text {th }}$ & $14^{\text {th }}$ & $21^{\text {st }}$ & $28^{\text {th }}$ \\
\hline G1 & 0.9865 & 1.2435 & 1.738 & 2.001 & 1.1385 & 0.470 \\
G2 & 0.760 & 1.1845 & 1.532 & 1.882 & 0.982 & 0.3749 \\
G3 & 0.173 & 0.198 & 0.397 & 0.2452 & 0.184 & 0.1025 \\
\hline
\end{tabular}

G (1) Chickens vaccinated by inactivated Combined vaccine with Montanide ${ }^{\mathrm{TM}}$ ISA RVG-71 oil adjuvant

G (2) Chickens vaccinated by inactivated Combined vaccine with paraffin oil adjuvant.

G (3): chicks kept as non-vaccinated control.

Table 4: macrophage activity of chicks vaccinated with combined inactivated avian AI [H5N1, H9N2] and IBV oil emulsion vaccines.

\begin{tabular}{|c|c|c|c|c|}
\hline \multirow{3}{*}{$\begin{array}{l}\text { Chick } \\
\text { group }\end{array}$} & \multicolumn{4}{|c|}{ Phagocytic activities days post vaccination } \\
\hline & \multicolumn{2}{|c|}{ Phagocytic $\%$} & \multicolumn{2}{|c|}{ Phagocytic index } \\
\hline & $7^{\text {th }}$ & $14^{\text {th }}$ & $7^{\text {th }}$ & $14^{\text {th }}$ \\
\hline G1 & $60.7 \%$ & $86.66 \%$ & 0.44 & 0.83 \\
\hline G2 & $54.54 \%$ & $78.8 \%$ & 0.46 & 0.76 \\
\hline G3 & $5.26 \%$ & $3.703 \%$ & 0.08 & 0.11 \\
\hline
\end{tabular}

G (1) Chickens vaccinated by inactivated Combined vaccine with Montanide ${ }^{\mathrm{TM}}$ ISA RVG-71 oil adjuvant

G (2) Chickens vaccinated by inactivated Combined vaccine with paraffin oil adjuvant.

G (3): chicks kept as non-vaccinated control.

Table 5: mean $\log 2 \mathrm{HI}$ antibody titer against $\mathrm{H} 5 \mathrm{~N} 1$ of chicks vaccinated with combined inactivated AIVs H5N1, H9N2 and IBV oil emulsion vaccines.

\begin{tabular}{ccccccccccccccccccc}
\hline $\begin{array}{c}\text { Chick } \\
\text { Grou } \\
\text { p }\end{array}$ & 1 & 2 & 3 & 4 & 5 & 6 & 7 & 8 & 9 & 10 & 12 & 15 & 17 & 19 & 21 & 23 & 27 & 31 \\
\hline \multirow{2}{*}{ G1 } & 5. & 7. & 10 & 9. & 10 & 9. & 8. & 8. & 8. & 7. & 8. & 7. & 8. & 6. & 7. & 6.0 & 4.6 & 4.3 \\
& 33 & 33 & 10 & 33 & & 66 & 66 & 00 & 66 & 66 & 66 & 00 & 00 & 66 & 33 & 0 & 6 & 3 \\
G2 & 4 & 4. & 6. & 7. & 8. & & 7. & 7. & 6. & 7 & 5. & 4. & & 4. & 4. & 4 & 2.6 & 1.3 \\
& & 3 & 6 & 6 & 3 & 8 & 6 & 3 & 6 & 7 & 3 & 6 & 5 & 3 & 3 & 4 & 6 & 3 \\
G3 & 0 & 0 & 0 & 0 & 0 & 0 & 0 & 0 & 0 & 0 & 0 & 0 & 0 & 0 & 0 & 0 & 0 & 0 \\
\hline
\end{tabular}


Table 6: mean $\log 2 \mathrm{HI}$ antibody titer against H9N2 of chicks vaccinated with combined inactivated AIVs H5N1, H9N2 and IBV oil emulsion vaccines.

\begin{tabular}{|c|c|c|c|c|c|c|c|c|c|c|c|c|c|c|c|c|c|c|}
\hline \multirow[b]{2}{*}{$\begin{array}{l}\text { Chick } \\
\text { Group }\end{array}$} & \multicolumn{18}{|c|}{ Mean $\log _{2} \mathrm{HI}$ antibody titer against H9N2 weeks post vaccination } \\
\hline & 1 & 2 & 3 & 4 & 5 & 6 & 7 & 8 & 9 & 10 & 12 & 15 & 17 & 19 & 21 & 23 & 27 & 31 \\
\hline G1 & $\begin{array}{l}5 . \\
6\end{array}$ & $\begin{array}{l}7 . \\
66\end{array}$ & $\begin{array}{l}9 . \\
3 \\
3\end{array}$ & 10 & $\begin{array}{l}9 . \\
66\end{array}$ & $\begin{array}{l}8 . \\
66\end{array}$ & $\begin{array}{l}9 . \\
66\end{array}$ & $\begin{array}{c}8 . \\
33\end{array}$ & $\begin{array}{l}7 . \\
33\end{array}$ & $\begin{array}{c}8 . \\
33\end{array}$ & $\begin{array}{c}8 . \\
33\end{array}$ & $\begin{array}{c}8 . \\
33\end{array}$ & $\begin{array}{l}8 . \\
66\end{array}$ & $\begin{array}{l}6 . \\
66\end{array}$ & $\begin{array}{l}7 . \\
00\end{array}$ & $\begin{array}{c}7.6 \\
6\end{array}$ & 6 & $\begin{array}{c}4.3 \\
3\end{array}$ \\
\hline G2 & $\begin{array}{l}3 . \\
00\end{array}$ & $\begin{array}{c}4 . \\
6\end{array}$ & $\begin{array}{l}6 . \\
6\end{array}$ & $\begin{array}{l}7 . \\
3\end{array}$ & 7.1 & 6 & $\begin{array}{c}5 . \\
6\end{array}$ & 6 & $\begin{array}{l}6 . \\
3\end{array}$ & $\begin{array}{c}6 . \\
6\end{array}$ & 7 & $\begin{array}{l}5 . \\
3\end{array}$ & $\begin{array}{c}4 . \\
6\end{array}$ & $\begin{array}{c}4 . \\
6\end{array}$ & 5 & 4 & $\begin{array}{c}2.6 \\
6\end{array}$ & $\begin{array}{c}1.0 \\
0\end{array}$ \\
\hline G3 & 0 & 0 & 0 & 0 & 0 & 0 & 0 & 0 & 0 & 0 & 0 & 0 & 0 & 0 & 0 & 0 & 0 & 0 \\
\hline
\end{tabular}

Table 7: ELISA antibody titers against IBV expressed as optical density of chicks vaccinated with combined inactivated AIVs H5N1, H9N2 and IBV oil emulsion vaccines.

\begin{tabular}{|c|c|c|c|c|c|c|c|c|c|c|c|c|c|c|c|}
\hline \multirow{2}{*}{$\begin{array}{c}\text { Chic } \\
\text { k } \\
\text { Grou } \\
\text { p }\end{array}$} & \multicolumn{15}{|c|}{ Mean antibody titer expressed of IBV as optical density weeks post vaccination } \\
\hline & 1 & 2 & 3 & 4 & 5 & 6 & 7 & 8 & 9 & 10 & 12 & 15 & 17 & 19 & 21 \\
\hline \multirow{2}{*}{ G1 } & 45 & 89 & 108 & 210 & 185 & 167 & 167 & 114 & 155 & 151 & 124 & 131 & 148 & 142 & 120 \\
\hline & 3 & 4 & 0 & 8 & 2 & 6 & 8 & 0 & 4 & 6 & 6 & 7 & 2 & 0 & 4 \\
\hline \multirow{2}{*}{$\mathrm{G} 2$} & 56 & 87 & 127 & 186 & 168 & 154 & 167 & 117 & 144 & 146 & 119 & 115 & 108 & \multirow{2}{*}{940} & \multirow[b]{2}{*}{542} \\
\hline & 8 & 0 & 0 & 2 & 0 & 0 & 9 & 7 & 0 & 8 & 7 & 4 & 0 & & \\
\hline G3 & 15 & 26 & 48 & 56 & 62 & 86 & 80 & 68 & 76 & 70 & 66 & 58 & 46 & 28 & 32 \\
\hline
\end{tabular}

Table 8: Protection percent in chicks vaccinated with combined inactivated AIVs H5N1, H9N2 and IBV oil emulsion vaccines after their challenge with virulent strain of (HPAIV) H5N1.

\begin{tabular}{ccccc}
\hline Chick & \multicolumn{3}{c}{ Number of chicks } & Protection \\
\cline { 2 - 4 } groups & Challenged & Dead & Live & Percent \\
\hline G1 & 50 & 0 & 50 & $100 \%$ \\
G2 & 50 & 8 & 42 & $84 \%$ \\
G3 & 50 & 50 & 0 & $0 \%$ \\
\hline
\end{tabular}

Table 9: Evaluation of virus shedding after challenge with AIV H9N2 of chicks vaccinated with combined inactivated AIVs H5N1, H9N2 and IBV oil emulsion vaccines using RRT-PCR.

\begin{tabular}{ccccc}
\hline Day post challenge & Group & Result & CT & Shedding amount (Copies) \\
\hline \multirow{3}{*}{ 2nd day } & 1-B & Negative & No Ct & - \\
& 2-B & Negative & No Ct & - \\
& 3-B & Positive & 26.23 & $3.854 \times 102$ \\
\hline \multirow{3}{*}{ 4th day } & 1-B & Negative & No Ct & - \\
& 2-B & Negative & No Ct & - \\
& 3-B & Positive & 23.15 & $5.278 \times 105$ \\
\hline \multirow{2}{*}{ 6th day } & 1-B & Negative & No Ct & - \\
& 2-B & Negative & No Ct & - \\
& 3-B & Positive & 24.64 & $2.377 \times 103$ \\
\hline
\end{tabular}

G1-B chicks are vaccinated with Combined Vaccine against H9N2 montanide71ISA RVG

G2-B chicks are vaccinated with Combined Vaccine against H9N2 paraffin oil adjuvant G3-B chicks kept as non-vaccinated control. 
Table 10: Evaluation of virus shedding after challenge with IBV of chicks vaccinated with combined inactivated AIVs H5N1, H9N2 and IBV oil emulsion vaccines using RRT-PCR.

\begin{tabular}{ccccc}
\hline Day post challenge & Group & Result & CT & Shedding amount (Copies) \\
\hline \multirow{3}{*}{ 2nd day } & 1-C & Negative & No Ct & - \\
& 2-C & Negative & No Ct & - \\
& 3-C & Positive & 22.89 & $4.832 \times 10^{7}$ \\
\hline \multirow{3}{*}{ 4th day } & 1-C & Negative & No Ct & - \\
& 2-C & Positive & 25.314 & $3.543 \times 10^{8}$ \\
& 3-C & Positive & 30.14 & $6.330 \times 10^{8}$ \\
6th day & 1-C & Negative & No Ct & - \\
& 2-C & Positive & 23.72 & $2.664 \times 10^{3}$ \\
& 3-C & Positive & 23.15 & $5.278 \times 10^{5}$ \\
\hline
\end{tabular}

G1-C chicks are vaccinated with Combined Vaccine against IBV with montanide71-ISA RVG

G2-C chicks are vaccinated with Combined Vaccine against IBV with paraffin oil adjuvant G3-C chicks kept as non-vaccinated control.

\section{DISCUSSION}

Inactivated AIVs H5N1, H9N2 and IBV (D-88) were used as the seed virus for vaccine preparation (OIE, 2008). Vaccines were prepared in the formula of water -in oil (W/O) emulsion using paraffin oil (Daoud et al., 2002; El-Sayed, 2014) and using Montanide $^{\mathrm{TM}}$ ISA 71 RVG adjuvant ((SEPPIC, France). Quality control of adjuvant emulsion has direct impact on the efficacy and the safety of vaccine. Physiochemical characterization of an emulsion can be defined by various parameters such as droplet test, conductivity, viscosity, particle size and stability at various temperatures. W/O emulsion requires high shear homogenization to get stable formulation (Salager 2000: Lissant 1984).

Drop test showed that the prepared combined inactivated AIVs H5N1, H9N2 and IBV oil emulsion vaccines using either Montanide $^{\text {TM }}$ ISA 71R VG and Paraffin oils as adjuvants were W/O emulsion type, and conductivity which measured by $(\mathrm{mS} / \mathrm{cm})$ unit equal (zero) as shown in table (2). These results were agreed with (Salager 2000: Lissant 1984).
Particle size for the prepared vaccines were $950 \mathrm{~nm}$ and $1050 \mathrm{~nm}$ and dynamic viscosities were 19.52 Mpa.s and 39.65 Mpa.s for combined inactivated AIVs H5N1, H9N2 and IBV vaccine with Montanide ${ }^{\mathrm{TM}}$ ISA 71R VG adjuvant and combined inactivated AIVs H5N1, H9N2 and IBV vaccine with Paraffin oil adjuvant, respectively. These results indicate fast flow time and easy injectability of the prepared vaccines and were agreed with Stone, (1991) and Seppic, (2012) who showed that ideal particle sizing between $0.05 \mu \mathrm{m}$ and $1000 \mu \mathrm{m}$ and was also like the results of the European pharmacopeia, (2010) which stated that acceptance limits of viscosity of vaccine emulsion ranged between $12 \geq R \leq 56$ mpa.s.

The prepared vaccines were stable soon after preparation using centrifugation test. They also were stable for 104 weeks at $4^{\circ} \mathrm{C}$ using real time test. These results came in accordance with Ben Arous et al., (2013) and El-Sayed, (2014). Also, were similar to the results of Lissant (1984), Stone, (1991) and Salager (2000).

The prepared combined inactivated AIVs H5N1, H9N2 and IBV oil emulsion vaccines were completely sterile with no bacterial or fungal contaminants when tested 
on specific bacteriologic and fungal media. In addition, absence of local and systemic reactions and no mortalities were recorded in inoculated chicks which denoted to the safety of the prepared vaccines. Results of the vaccines sterility and safety came in parallel with the recommendations of OIE, (2004).

Evaluation of the potency of both combined inactivated oil emulsion vaccines using either Montanide ${ }^{\mathrm{TM}}$ ISA 71R VG and Paraffin oils as adjuvants were carried out in vaccinated chicks through measuring cellular and humoral immune responses and protection percent after their challenge.

Lymphocyte blastogenesis showed significant cell proliferation expressed by optical density induced in vaccinated chicks vaccinated by both inactivated combined vaccines with Montanide ${ }^{\text {TM }}$ ISA 71-RVG oil adjuvant and paraffin oil adjuvants from the $3^{\text {rd }}$ day post vaccination (DPV) and increased to reach a maximum value $14^{\text {th }} \mathrm{DPV}$. It was noticed that chicks vaccinated with

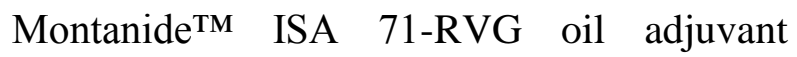
showed higher values than that of chicks vaccinated with paraffin oil adjuvant (table 3 ). Both phagocytic percent and phagocytic index of macrophages were significantly increased $7^{\text {th }}$ DPV to reach maximum values at $14^{\text {th }}$ DPV in vaccinated chicks with both Montanide $^{\mathrm{TM}}$ ISA 71-RVG oil adjuvant and paraffin oil adjuvant (table 4). These results came in agreement with that of (Madkour 1992) who clarified clearly that chicken vaccinated with oil emulsion vaccine greatly stimulated the cellular immune response as estimated by lymphocyte proliferation test. The results also showed that values of cellular immune response at later stages came in agreement with that of Timms and bracemell, (1983) who stated that once the humoral immune response becomes established there is a corresponding decrease in the cellular immune response.
Humoral immune response induced by the prepared vaccines were comparatively evaluated for chick groups vaccinated with combined inactivated AIVs H5N1, H9N2 and IBV oil emulsion vaccine using either Montanide $^{\mathrm{TM}}$ ISA 71R VG and Paraffin oils as adjuvants.

For AIV H5N1, chicks vaccinated with Montanide $^{\mathrm{TM}}$ ISA 71-RVG oil adjuvant vaccine, showed increased mean $\log 2 \mathrm{HI}$ antibody titer $(5.33 \log 2)$ from the 1 st week post vaccination (WPV), then reached the highest HI antibody titer $(10 \log 2)$ at the $3^{\text {rd }}$ WPV and remained in suitable levels (4.33 $\log 2$ ) till $31^{\text {st }}$ WPV. On the other hand, chicks vaccinated with paraffin oil adjuvant vaccine, showed increased mean $\log 2 \mathrm{HI}$ antibody titer (4 $\log 2$ ) from the 1 st week post vaccination (WPV), then reached the highest HI antibody titer $(8.3 \log 2)$ at the $5^{\text {th }}$ WPV, then declined to $(4.3 \log 2)$ at the $21^{\text {st }}$ WPV then declined gradually to reach the lowest HI antibody titer $(1.33 \log 2)$ at the $31^{\text {st }}$ WPV (table 5).

For AIV H9N2, chicks vaccinated with Montanide $^{\mathrm{TM}}$ ISA 71-RVG oil adjuvant vaccine, showed increased mean $\log 2 \mathrm{HI}$ antibody titer $(5.6 \log 2)$ from the 1 st week post vaccination (WPV), then reached the highest $\mathrm{HI}$ antibody titer $(10 \log 2)$ at the $4^{\text {th }}$ WPV and remained in suitable levels (4.33 $\log 2)$ till $31^{\text {st }}$ WPV. Chicks vaccinated with paraffin oil adjuvant vaccine, showed increased mean $\log 2 \mathrm{HI}$ antibody titer $(3 \log 2)$ from the 1st week post vaccination (WPV), then reached the highest $\mathrm{HI}$ antibody titer (7.3 $\log 2)$ at the $4^{\text {th }}$ WPV, then declined to (4 $\log 2$ ) at the $23^{\text {rd }}$ WPV then declined gradually to reach the lowest HI antibody titer (1.0 $\log 2$ ) at the $31^{\text {st }}$ WPV (table 6). The results similar to Swayne et al., (1997) and Swayne et al., (2000) who proved that the best vaccines produce protection beginning in 7 to 10 days after vaccination with the peak protection at 3 to 4 weeks and protection may 
last up to 6 to 12 months. Also, these results came in accordance with that of Qiau et al., (2006) who proved the maximal level of antibodies of (highly pathogenic strain A/goose/Guangdong/1/96 (H5N1) 1:1024 was recorded on the $6^{\text {th }}$ week. Also, these findings came in agreement with that of Zhailyaubay et al., (2010) who showed that the high immunogenicity of the AI- inactivated emulsified vaccine H5N1 developed by using Montanide $^{\text {TM }}$ ISA- 70 (Seppic, France) as oil adjuvant, showing hemagglutinating antibodies were detected in 14 days and reached their peak of $1: 277$ on the $6^{\text {th }}$ week post vaccination.

Concerning IBV, chicks vaccinated with Montanide $^{\text {TM }}$ ISA 71-RVG oil adjuvant vaccine, showed increased antibody titer measured by mean ELISA optical density (453) from the 1st WPV, then reached the highest values $(2108)$ at the $4^{\text {th }} \mathrm{WPV}$ and remained in suitable levels (1204) till $21^{\text {st }}$ WPV. Chicks vaccinated with paraffin oil adjuvant vaccine, showed increased antibody titer measured by mean ELISA optical density (586) from the 1st WPV, then reached the highest HI antibody titer (1862) at the $4^{\text {th }}$ WPV, then declined to (542) at the $21^{\text {st }}$ WPV (table 7). Finding came in agreement with that of Sultan et al., (2004) and El-Mahdy et al., (2010) who clarify the role of the Mass41 (M41) strain which is commonly used in inactivated vaccines, also the finding came in agreement with that of Muneer et al., (1986) who proved that the inactivated oil-emulsion IBV vaccines are commonly used to obtain long-lasting immunity to protect breeders and layers prior to the onset of the egg production. The results also like Tewfik et al., (2013) who showed D88 strain was the best protectotype where it gave an excellent immune response at the 3 rd day post challenge.

Both vaccinated and non-vaccinated control chicks were challenged 28 days post vaccination using virulent strains of AIVs H5N1, H9N2 and IBV. The protection percent against HPAIV H5N1 were $100 \%$ in chicks vaccinated with Montanide ${ }^{\mathrm{TM}}$ ISA 71-RVG oil adjuvant vaccine and $84 \%$ in chicks vaccinated with paraffin oil adjuvant vaccine (table 8). These results came in accordance with that of Zhailyaubay et al., (2010) who showing hemagglutinating inhibiting antibodies were detected in 14 days and reached their peak of 1:277 on the 6th week post vaccination. $100 \%$ protection against infection since 28 day post vaccination up to 150 days; then slowly going down to $80 \%$ (the rate sufficient for ensuring safety of the vaccinated poultry) by the $360^{\text {th }}$ day post vaccination.

Evaluation of shedding of AIV H9N2 were zero \% using RRT-PCR in challenged chicks vaccinated with Montanide ${ }^{\mathrm{TM}}$ ISA 71RVG oil adjuvant vaccine and paraffin oil adjuvant vaccine, compared with $100 \%$ shedding for control non-vaccinated chicks in tracheal swaps at $2^{\text {nd }}, 4^{\text {th }}$ and $6^{\text {th }}$ day post challenge as shown in table (9). These results came in accordance with Jeong et al, (2015) who proved that the administration of the inactivated AIV H9N2 vaccine is highly effective in decreasing the clinical signs and virus shedding of flocks. Also, these results disagree with Swayne et al., (1997; Swayne et al., (2000) who proves that the vaccines may protect from morbidity and mortality but not reduce replication and shedding from respiratory and digestive tracts also, the greater the genetic similarity between the HA of vaccine and field viruses, the greater is the reduction in challenge virus replication and shedding from the respiratory tract.

Evaluation of shedding of IBV were zero \% using RRT-PCR in challenged chicks vaccinated with Montanide TM ISA 71-RVG oil adjuvant vaccine but the shedding of IBV using RRT-PCR in challenged chicks 
vaccinated with paraffin oil adjuvant vaccine, were zero $\%$ at $2^{\text {nd }}$ day post challenge then shedding occurred at $4^{\text {th }}$ and gradually declined $6^{\text {th }}$ day post challenge, compared with $100 \%$ shedding for control nonvaccinated chicks in tracheal swaps at $2^{\text {nd }}, 4^{\text {th }}$ and $6^{\text {th }}$ day post challenge as shown in table (10). These Finding came in agreement with that of Tewfik et al., (2013) who showed D88 strain was the best protectotype where it gave an excellent immune response at the 3rd day post challenge. The protection $\%$ was $100 \%$ in both trachea and kidney virus re-isolation

In conclusion, combined inactivated AIVs H5N1, H9N2 and IBV oil emulsion vaccine using either MontanideTM ISA 71R VG and Paraffin oils as adjuvants showed suitable cellular and humoral immune responses in vaccinated chicks but with superior results for the vaccine with Montanide $^{\mathrm{TM}}$ 71-RVG adjuvant that also provided $100 \%$ protection percent for AIV H5N1 and no secretion of AIV H9N2 and IBV in comparison to the combined vaccine with paraffine oil adjuvant that gave $84 \%$ protection percent for AIV H5N1 and secretion of AIV H9N2 and IBV occurred $6^{\text {th }}$ day post challenge.

Finally, Montanide ${ }^{\mathrm{TM}}$ 71-RVG adjuvant has the flexible ratio of oil and antigenic media in the vaccine (60:40) allowed using large amount of virus that showed good impact on its immunogenicity, other than mineral oil adjuvant which is restricted Ratio of oil and antigenic media of vaccine (73:27).

\section{REFERENCES}

Abbas, M.A., Spackman, E., Swayne, D.E., Ahmed, Z., Sarmento, L., Siddique, N., Naeem, K., Hameed, A., Rehmani, S. 2010. Sequence and phylogenetic analysis of $\mathrm{H} 7 \mathrm{~N} 3$ avian influenza viruses isolated from poultry in Pakistan 1995-2004. Virol J.; 7:137.

Abd El Rahman, S.; Hoffmann, M.; Lueschow, D.; Eladl, A.; Hafez, H.M. 2015. Isolation and characterization of new variant strains of infectious bronchitis virus in Northern Egypt. Adv. Anim. Vet. Sci., 3: 362-371.

Abdel-Moneim, A.S., Afifi, M.A., El-Kady, M.F. 2012a. Isolation and mutation trend analysis of influenza $\mathrm{A}$ virus subtype H9N2 in Egypt. Virology journal; 9:173.

Abdel-Moneim, A.S.; Afifi, M.A.; El-Kady, M.F. 2012b. Emergence of a novel genotype of avian infectious bronchitis virus in Egypt. Arch. Virol., 157: 24532457 [PMID: 22903394 DOI: 10.1007/ s00705-012-1445]

Abdel-Moneim, A.S., El-Kady,M.F., Ladman,B.S.; Gelb, J.Jr. 2006. S1 gene sequence analysis of a nephropathogenic strain of avian infectious bronchitis virus in Egypt. Virol. J. 3, 78, doi:10.1186/1743422X-3-78.

Alexander, D. J. 2000. A review of Avian Influenza in different bird specious. Vet. Microbial 74, 3-13.

Aly, M.M.; Hassan, M.K.; Arafa, A. 2006. Emergence of highly pathogenic H5N1 avian influenza virus in poultry in Egypt. First record of 2006 outbreaks. J. Egypt. Vet. Med. Assoc., vol.66 (2): 263-

Anon, 1971. Methods of examine poultry biologics for identifying and quantifying avian pathogens. Nat. Acad. Sci. Washington DC.

Arafa, A.S., Hagag, N., Erfan, A., Mady, W., 
El-Husseiny, M., Adel, A., Nasef, S. 2012a. Complete genome characterization of avian influenza virus subtype H9N2 from a commercial quail flock in Egypt. Virus genes; 45:283-294.

Arafa, A.S., Hagag, N.M. Yehia, N. Zanaty, A.M. Naguib, M.M., Nasef, S.A. 2012b. Effect of co-circulation of highly pathogenic avian influenza H5N1 subtype with low pathogenic H9N2 subtype on the spread of infections". Avian Dis., 56: 849-857.

Beard, C.W. 1989. Influenza, in: "isolation and identification of avian pathogens", (editorial committee of American association of avian pathologists), $3^{\text {rd }}$ edition, Kendall-hunt publishing Co., Dubuque, IA, 110-113.

Ben Arous, J.; Deville, S.; Norkina, S.; Borisov, V.; Rozhdestvenskaia, T.; Rozhdestvenskiy, I.; Gaucheron, J.; Dupuis, L. 2013. Montanide ${ }^{\text {TM }}$ ISA 71 RVG: A robust and flexible adjuvant formulation for potent and stable poultry vaccines. Egg-Broiler, September 2013, www.vivekanandapublications.info.

Ben Shabat, M.; Meir, R.; Haddas, R.; Lapin, E.; Shkoda, I. Raibstein, I. Perk, S.; Davidson, I. 2010. Development of a real-time TaqMan RT-PCR assay for the detection of H9N2 avian influenza viruses. J Virol Methods.; 168 (1-2):727.

Brugh, M.; Stone, H.D.; Lupton, H.W. 1983. Comparison of inactivated Newcastle disease viral vaccines containing different emulsion adjuvants. Am. J. Vet. Res.; 44(1):72-75.

Cameron, K.R.; Gregory, V.; Banks, J.;
Brown, I.H.; Alexander, D.J.; Hay, A.J.; Lin, Y.P. 2000. H9N2 subtype influenza $A$ viruses in poultry in Pakistan are closely related to the H9N2 viruses responsible for human infection in Hong Kong. Virology.;278:36-41

Capua, I.; Alexander, D.J. 2004. Review Article Avian influenza: recent developments Avian Pathology., 33(4), 393-404.

Carstens E. 2009. Report from the 40th meeting of the Executive Committee of the International Committee of Taxonomy of Viruses, 2009: 15711574 [DOI: 10.1007/s00705-009-0458$\mathrm{x}]$.

Daoud, A., Mohamed, S.M., Nabil A.A., Ensaf, K., Salwa, E., 2002. Studies for improvement of inactivated oil emulsion Newcastle disease virus vaccine, 6th Vet. Med. Zag. Conference (7-9 sept.2002), Hurghada.

Dugan, V.G.; Chen, R.; Spiro, D.J.; Sengamalay, N., Zaborsky, J.; Ghedin, E.; Nolting, J.; Swayne, D.E.; Runstadler, J.A.; Happ, G.M.; Senne, D.A., Wang, R.; Slemons, R.D.; Holmes, E.C.; Taubenberger, J.K. 2008. The evolutionary genetics and emergence of avian influenza viruses in wild birds. PloS Pathogens, Volume 4, Issue 5, www.plospathogens.org. https://doi.org/10.1371/journal.ppat.10 00076

El-Mahdy, Susan, S.; El-Hady, M.M.; Soliman, Y.A. 2010. Isolation and characterization of Nephropathogenic strain of infectious Bronchitis virus in Egypt; Journal of American Science 6 (9) 669-674. 
El-Sayed, M.H.M. 2014. Improving the physical characters and immunological response of locally prepared oil emulsion ND vaccine, Thesis for the degree of P.H.D., (Virology) Faculty of Veterinary Medicine, Benha University.

European pharmacopeia 7th rev 2010 p27.

Fouchier, R.A.; Munster, V.; Wallensten, A.; Bestebroer, T.M.; Herfst, S.; Smith, D.; Rimmelzwaan, G.F.; Olsen, B.; Osterhausm, A.D. 2005. "Characterization of a novel influenza A virus haemagglutinin subtype (H16) obtained from black-headed gulls", J. Virol. 79 (5): 2814-22.

Garcia, M.; Suarez, D.J.; Crawford, J.M.; Latimer, J.W.; Slemons, R.D.; Swayne, D.E.; Perdue, M.I. 1998. Evaluation of H5 subtype avian influenza A viruses in North America. Virus Res.51, 115124.

Gelb, J.; Wolff, J.B.; Moran, C.A. 1995. Variant serotypes of infectious bronchitis virus isolated from commercial layer and broiler chickens. Avian Dis.; 35: 82-87.

Guo, Y. 2002. Influenza activity in China: 1998-1999. Vaccine 20, 28-35.

Haqshenas, G.; Asasi, K.; Akrami, H. 2005. Isolation and molecular characterization of infectious bronchitis virus isolate Shiraz 3. IBV, by RT-PCR and restriction enzyme analysis. Iranian J. Vet. Res. 6, 9-15.

Heba N. El-Behery; Sanaa S. Awad; Kasem, S.G. 2016. Molecular Characterization of Infectious Bronchitis Virus in Chicken. Egypt. J. Vet. Sci. Vol. 47. No, 2 pp. 133-149.
Hussein, H.A. 1989. Immunosuppressive effect of MDV. M.V.SC, thesis (Virology), Faculty of Veterinary Medicine, Cairo University.

Jeong, H.S.; Jong, S.M.; Jong, N.K., Inpil, M., Bong, D.H. 2015. Assessment of the safety and efficacy of low pathogenic avian influenza (H9N2) virus in inactivated oil emulsion vaccine in laying hens. Jun. 2015 in Safe and efficacious avian influenza virus H9N2 vaccine , Email:ha9975@hanmail.net

Jeong, O.M.; Kim, Y.J.; Choi, J.G.; Kang, H.M.; Kim, M.C.; Kwon, J.H.; Lee, Y.J. 2010. Genetic characterization of $\mathrm{H} 1$ avian influenza viruses isolated from migratory birds and domestic ducks in Korea. Virus Genes; 42:5563.

Kaoud, H. 2017. Avian Influenza in Egypt. Appro Poult Dairy \& Vet Sci. 1(4). APDV.000519.

Kayali, G., Kandeil, A.; El-Shesheny, R.; Kayed, A.S.; Gomaa, M.M.; Maatouq, A.M.; Shehata, M.M.; Moatasim, Y.; Bagato, O.; Cai, Z.; Rubrum, A.; Kutkat, M.A.; Pamela P. McKenzie; Webster, R.G.; Webby, R.J.; Ali, M.A. 2014." Active surveillance for avian influenza virus", Egypt, 2010-2012. Emerg Infect Dis., 20: 542-551.

Kayali, G.; Kandeil, A.; El-Shesheny, R; Kayed, AS.; Asmaa M. Maatouq; Cai, Z.; Pamela P. McKenzie; Webby, R.J.; El Refaey, S.; Kandeel, A.; Ali, M.A. 2016. Avian influenza $\mathrm{A}(\mathrm{H} 5 \mathrm{~N} 1)$ virus in Egypt. Emerging infectious diseases; 22(3): DOI 10.3201/eid2203.150593

Kim, J.K., Kayali, G.; Walker, D.; Forrest, H.L.; Ellebedy, A.H.; Griffin, Y.S.; 
Rubrum, A.; Bahgat, M.M.; Kutkat, M.A.; Ali, M.A.; Aldridge, J.R.; Negovetich, N.J.; Krauss, S.; Webby, R.J.; Webster, R.G.; 2010. Puzzling inefficiency of $\mathrm{H} 5 \mathrm{~N} 1$ influenza vaccines in Egyptian poultry. Proc. Natl. Acad. Sci. USA 107:11044 11049.

Lee, L.F. 1984. Proliferative response of chicken $\mathrm{B}$ and $\mathrm{T}$ lymphocyte to mitogen. Vet. Med; 15:44-52.

Lissant, K.J.L. 1984. Emulsions and emulsion technology, part III. In: Lissant Kenneth J, editor. Surfactant Science Series, vol. 6, pp:206-10.

Liu, S.; Kong, X. 2004. A new genotype of nephropathogenic infectious bronchitis virus circulating in vaccinated and nonvaccinated flocks in China. Avian Pathol.; 33: 321-327.

Lucy, F.L. 1977. Chicken Lymphocyte stimulation by mitogenes. A microassay with whole blood cultures. Avian Dis.; 22,296-307.

Madkour, M.S. 1992. Study of immunological comparative on live and killed Newcastle disease vaccine in poultry. M.D.V.Sci. (Immunology), Cairo university.

Meir, R.; Maharat, O.; Farnushi, Y.; Simanov, L. 2010. Development of a real-time TaqMan ${ }^{\circledR}$ RT-PCR assay for the detection of infectious bronchitis virus in chickens, and comparison of RTPCR and virus isolation. Journal of Virological Methods, 163: 190-194.

Mo, I.; Brugh, P.M.; Fletcher, O.J.; Rowland, G.N.; Swayne, D.E. 1997. Comparative pathology of chickens experimentally inoculated with avian influenza viruses of low and high pathogenicity. Avian Dis 41:125-136.

Monne, I.; Hussein, H.A.; Fusaro, A.; Valastro, V.; Hamoud, M.M.; Khalefa, R.A.; Dardir, S.N.; Radwan, M.I.; Capua, I.; Cattoli, G. 2013. "H9N2 influenza A virus circulates in $\mathrm{H} 5 \mathrm{~N} 1$ endemically infected poultry population in Egypt". Influenza Other Respir Viruses, 7: 240-243.3.

Muneer, M.A.; Halvorson, D.A.; Sivanandan, V.; Newman, J.A.; Coon, C.N. 1986. "Effects of infectious bronchitis virus (Arkansas strain) on laying chickens." Avian Dis.; 30 (4): 644-7.

Nagarajan, S.; Rajukumar, K.; Tosh, C.; Ramaswamy, V.; Purohit, K.; Saxena, G.; Behera, P.; Pattnaik, B.; Pradhan, H.K.; Dubey, S.C. 2009. Isolation and pathotyping of H9N2 avian influenza viruses in Indian poultry. Vet Microbiol.;133:154-63.

Nouri, A.; Asasi, K.; SeyfiI Abad Shapouri, M.R. 2003. Field study of Infections Bronchitis virus in broiler using typespecific c RT-PCR-Archives of Razi Institute, 55, 1-9.

OIE-Manual, 2004. Manual of standards of diagnostic tests and vaccines. Avian infectious bronchitis, 4th edn. pp. 569 561.

OIE, 2008. Manual of Diagnostic Tests and Vaccines for Terrestrial Animals, Office International des Epizooties, Paris, France: Pp.: 443-455.chapter 2.3.2. World Organization for Animal Health.

Olsen, B.; Munster, V.J.; Wallensten, A.; Waldenstrom, J.; Osterhaus, A.D. 2006. Global patterns of influenza a virus in wild birds. Science. 312:384- 
8.

Peyre, M.; Desvaux, S.; Fusheng, G. 2007. Avian Influenza Vaccine Development, Practical Applicationin Developing Countries. Proceedings of the 12th International Conference of the Association of Institutions for Tropical Veterinary Medicine، Montpellier, France 20-22 August.

Qiau, Ch.; Tian, G.; Jiang, Y.; Li, Y.; Shi, J.; Yu, K., Chen, H. 2006. Vaccines Developed for H5 Highly Pathogenic Avian Influenza in China. J Ann. NY Acad Sci, 1081, 182- 192.

Reed, L.J.; Mennch, H. 1938. Simple method for estimating 50 percent end point, Amer. J. Hyg; 27: 793-799.

Richardson, M.D.; Smith, H. 1981. Resistance of virulent and attenuated strains of Candida albicans to intracellular killing by human and mouse phagocytes. J. Infect. Dis.; 144:557-565.

Sjaak de Wit, J.J.; Cook, J.K.; van der Heijden, H.M. 2011. Infectious bronchitis virus variants: a review of the history, current situation and control measures. Avian Pathol., 40: 223-235 [PMID: 21711181 DOI: 10.1080/03079457.2011.56626]

Salager, J.L. 2000. Formulation concepts for emulsion maker. In: Nielloud $F$, Mestres GM. editors pharmaceutical emulsion and suspension and pharmaceutical science; 2000:19-68.

Schick, M.J. 1966. Nonionic surfactant, Marchel dekker In New york: 609-611.

Scudiero, D.A.; Shoemaker, R.H.; Paull, K.D.; Monks, A.; Tierney, S.; Nofziger, T.H.; Currens, M.J.; Seniff, D.; Boyd, M.R. 1988. Evaluation of soluble tetrazolium / Formazan Assay for cell growth and drug sensitivity in culture using human and other tumer cell lines. Cancer Res.; 48:4827-4833

Seppic, 2012. Montanide selection for avian vaccines, Seppic poultry seminar, Dubai, 2012. Seppic limited Incorporation Company.

Shapouri, S.A.; Mayahi, M.; Assasi, K.; Charkhkar. S. 2004. A survey of the prevalence of infectious bronchitis virus type 4/91 in Iran. Acta. Vet. Hung. 52:163-166.

Snyder, D.B.; Marguardt, W.W.; Mallinion, E.T.; Russetcohen E.; Svage, P.K.; Allen, D.C. (1986): Rapid serological profiling by enzyme linked immunosorbent assay. Avian Dis., 30:139148.

Stone, H.D. 1987. Efficacy of avian influenza oil-emulsion vaccines in chickens of various ages. Avian Dis., 31: 483-490.

Stone, H.D. 1988. "Optimization of hydrophile-lipophile balance for improve efficacy of Newcastle disease and avian influenza oil-emulsion vaccines "Avian Dis.; 32 (1): 68-73.

Stone, H.D. 1991. "The preparation and efficacy of manually emulsified Newcastle disease oil-emulsion vaccines" Avian disease 35:8-16, 1991.

Stone, H.D.; Brugh, M.; Bread, C.W. 1983. "influence of formulation on the efficacy of experimental oil-emulsion Newcastle disease vaccines" Avian Diseases., 27:.688-697.

Sultan, H.A.; Tancawi, L.; Youseif, A.I.; Ahmed, A.A.S. 2004. Urolithiathesis in white commercial egg laying chickens associated with an infectious bronchitis 
virus. 6th Sci. Conf. Egypt. Vet. Poult. Assoc., 155-169.

Sultan, H.; Abdel-Razik, A.G.; Shehata, A.A.; Ibrahim, M.; Talaat, S.; Abo-Elkhair, M., Bazid, A.E.; Moharam, I.M.; Vahlenkamp, T. 2015. Characterization of Infectious Bronchitis Viruses Circulating in Egyptian chickens during 2012 and 2013. J. Vet. Sci. Med. Diagn., 4: 5 [DOI: 10.4172/23259590.1000180]

Swayne, D.E.; Beck, J.R.; Micckle, T.R. 1997. Efficacy of recombinant fowl poxvirus vaccine in protecting chickens against a highly pathogenic Mexicanorgin H5N2 avian influenza virus Avian Dis. 41(4):910-922.

Swayne, D.E.; Garcia, M.; Beck, J.R.; Kinney, N.; Suarez, D.L. 2000. Protection against diverse highly pathogenic avian influenza viruses in chickens immunized with a recombinant fowl pox vaccine containing an $\mathrm{H} 5$ avian influenza haemagglutinin gene insert. Vaccine 18(11-12):1088-1095.

Tawfik, H.I.; Salama. E., Hassan, O.M.; Ahmed, A. 2013. Preparation and evaluation of live bivalent infectious bronchitis vaccine in chicken. Researcher 2013;5(3) http://www.sciencepub.net/researcher.

Timms, L.M.; Bracemell, C.D. 1983. Cell mediated and humoral immune response of chickens to inactivated oil emulsion infectious bronchitis vaccine. Res. Vet. Sci., 34:224-230

Xu, K.M.; Li, K.S.; Smith, G.J.; Li, J.W.; Tai, H.; Zhang, J.X.; Webster, R.G.; Peiris, J.S.; Chen, H.; Guan, Y. 2007. Evolution and molecular epidemiology of H9N2 influenza A viruses from quail in southern China, 2000-2005. J. Virol., 81, 2635-2645.

Zhailyaubay, K.K.; Kaissar, K.T.; Sholpan, Zh.R.; Seidigapbar, M.M.; Berik M.K. 2010. "Immunogenicity of the inactivated oil emulsion influenza (H5N1) vaccine in chickens". Agric. Biol. J. N. Am., 1(3): 201-207. 